\section{Commentary: Papillary muscle relocation for secondary mitral regurgitation: A never-ending story}

\author{
Giacomo Murana, MD, $\mathrm{PhD}$, and \\ Davide Pacini, MD, PhD
}

Secondary (functional) mitral regurgitation (MR) is a welldescribed pathophysiological entity as a result of left ventricular dysfunction, dislocation of papillary muscles, and subsequent tethering of the mitral leaflets. Various operative techniques have been proposed with the aim to correct the altered mitral valve apparatus at different levels using undersizing annuloplasty alone or in conjunction with papillary muscle relocation or even with chordal cutting. However, all of these therapeutic options have been associated with early or late recurrence of MR and most of them were abandoned. The Cardiothoracic Surgical Trials Network $^{1}$ demonstrated that repairs with annuloplasty fail, thus replacement is warranted. But when patients with a durable repair in this study were compared with replacement, their 2-year mortality was $9 \%$ versus $23 \%$ and their left ventricular end systolic diameter was $44 \mathrm{~mm}$ versus $65 \mathrm{~mm}$. Probably, when durable surgical repair could be achieved, it would still be associated with better outcome compared with replacement. The debate is how to determine candidacy for mitral repair, and eventually how to surgically treat these patients with functional MR.

In a very interesting article, a group from Atlanta propose a biomechanical study to close this gap. ${ }^{2}$ The authors developed a chronic swine model of ischemic MR to test the hypothesis that papillary muscle approximation (PMA) relieves tethering forces and improves coaptation geometry and hemodynamics. ${ }^{2}$ Results demonstrated that PMA relieves tethering forces (reduced tenting area to

\footnotetext{
From the Division of Cardiac Surgery, IRCCS, Azienda Ospedaliero-Universitaria di Bologna, Bologna, Italy.

Disclosures: The authors reported no conflicts of interest.

The Journal policy requires editors and reviewers to disclose conflicts of interest and to decline handling or reviewing manuscripts for which they may have a conflict of interest. The editors and reviewers of this article have no conflicts of interest.

Received for publication May 16, 2021; revisions received May 16, 2021; accepted for publication May 21, 2021; available ahead of print June 7, 2021.

Address for reprints: Davide Pacini, MD, PhD, Division of Cardiac Surgery, S. Orsola Hospital, University of Bologna, Via Massarenti 9, 40138 Bologna, Italy (E-mail: davide.pacini@unibo.it).

JTCVS Open 2021;7:105-6

2666-2736

Copyright (c) 2021 The Author(s). Published by Elsevier Inc. on behalf of The American Association for Thoracic Surgery. This is an open access article under the CC BY-NC-ND license (http://creativecommons.org/licenses/by-nc-nd/4.0/).

https://doi.org/10.1016/j.xjon.2021.05.007
}

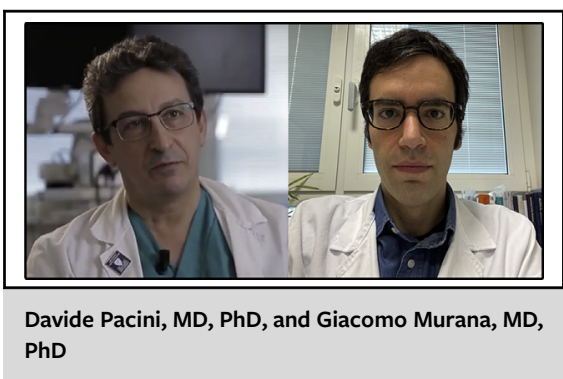

\section{CENTRAL MESSAGE \\ Correcting the subannular appa- ratus in secondary mitral regur- gitation makes the difference.}

$27.31 \pm 43.38 \mathrm{~mm}^{2}$ ) and, when added to annuloplasty, restores physiological leaflet mobility and significantly reduces the regurgitant fraction (from $16.3 \%$ to $3.7 \%$ ).

In comparison to previous studies on the same subject, the article has the merit to:

- Be translational. Other evidence-based studies like that from Hvass and colleagues, ${ }^{3}$ Nappi and colleagues, ${ }^{4}$ and Fattouch and colleagues ${ }^{5}$ reported favorable results when acting on papillary muscles, but all of them were retrospective clinical series based on the limitations coming from surgical practice. The study from Zhan-Moodie and colleagues ${ }^{2}$ is the first to provide the mechanistic basis for adopting PMA.

- To test the mitral valve under different conditions. At baseline, after induction of a functional MR, after undersizing annuloplasty (to $30 \mathrm{~mm}$ and $26 \mathrm{~mm}$ ), and after concomitant PMA with both ring sizes. This meticulous approach corroborates the initial hypothesis and demonstrates the effectiveness of adding PMA without the need for extensive annular downsizing.

Despite all these interesting aspects, the possibility to correct severe functional MR should also consider the lack of data on long-term durability and the widespread availability of less-invasive transcatheter devices. The Cardiovascular Outcomes Assessment of the MitraClip Percutaneous Therapy Trial for patients with secondary MR demonstrated improvement in survival, hospitalization, symptoms, and quality of life in patients with persistent symptoms and left ventricle dysfunction (mean left ventricular endsystolic dimension, $52 \pm 9 \mathrm{~mm}$, mean left ventricular enddiastolic dimension, $62 \pm 7 \mathrm{~mm}$, left ventricular ejection fraction between $20 \%$ and $50 \%$, and mean effective regurgitant orifice area, $0.31 \mathrm{~cm}^{2}$ ) compared with those randomized to medical therapy. ${ }^{6}$ These important facts could justify 
a first reconstructive attempt on the mitral valve using a less-invasive approach instead of a more-invasive open procedure, regardless of the duration of the result.

Similar experimental studies should always be encouraged in the surgical community to support the efficacy of new treatments, but to be effective, results should also be translated into clinical practice and validated over time. In the meantime, surgical treatment of secondary MR should follow the recommendations of practice guidelines ${ }^{7}$ and chordalsparing mitral valve replacement be preferred over repair.

\section{References}

1. Michler RE, Smith PK, Parides MK, Ailawadi G, Thourani V, Moskowitz AJ, et al. Two-year outcomes of surgical treatment of moderate ischemic mitral regurgitation. N Engl J Med. 2016;374:1932-41.

2. Zhan-Moodie S, Xu D, Suresh KS, He Q, Onohara D, Kalra K, et al. Papillary muscle approximation reduces systolic tethering forces and improves mitral valve closure in the repair of functional mitral regurgitation. J Thorac Cardiovasc Surg Open. 2021;7:91-104.

3. Hvass U, Tapia M, Baron F, Pouzet B, Shafy A. Papillary muscle sling: a new functional approach to mitral repair in patients with ischemic left ventricular dysfunction and functional mitral regurgitation. Ann Thorac Surg. 2003;75: 809-11.

4. Nappi F, Lusini M, Spadaccio C, Nenna A, Covino E, Acar C, et al. Papillary muscle approximation versus restrictive annuloplasty alone for severe ischemic mitral regurgitation. J Am Coll Cardiol. 2016;67:2334-46.

5. Fattouch K, Murana G, Castrovinci S, Mossuto C, Sampognaro R, Borruso MG, et al. Mitral valve annuloplasty and papillary muscle relocation oriented by 3dimensional transesophageal echocardiography for severe functional mitral regurgitation. J Thorac Cardiovasc Surg. 2012;143:S38-42.

6. Stone GW, Lindenfield J, Abraham WT, Kar S, Lim DS, Mishell JM, et al. Transcatheter mitral-valve repair in patients with heart failure. N Engl J Med. 2018;379: $2307-18$.

7. Otto CM, Nishimura RA, Bonow RO, Carabello BA, Erwin JP III, Gentile F, et al. 2020 ACC/AHA guideline for the management of patients with valvular heart disease: a report of the American College of Cardiology/American Heart Association Joint Committee on clinical practice guidelines. J Am Coll Cardiol. 2021;77: e25-197. 